THE KURUME MEDICAL JOURNAL Vol. 6, No. 1, 1959

\title{
AN EXPERIMENTAL STUDY ON A NEW FINAL HOST OF GNATHOSTOMA SPINIGERUM
}

\author{
MITSURU SHIRAKAWA \\ Department of Hygiene and Public Health, Kurume University \\ School of Medicine, Kurume, Japan
}

\section{PREFACE}

Since Owen discovered Gnathostoma spinigerum in the stomach of a tiger at London in 1836, the final hosts of this nematode were found in cats, dogs and leopards as a natural infection, and experimentally in cats and dogs. In the fox, however, there were no reports of either natural infection or experimental infection of this nematode.

The author obtained some adult gnathostomes from a fox experimentally infected with the larvas parasitic in Ophicephalus argus, detected many eggs of this nematode in the feces in its rectum, and confirmed experimentally that it is possible for a fox to be the final host of this gnathostome. The results obtained are as follows:

\section{EXPERIMENTAL PROCEDURE AND RESULTS}

At the beginning of August, 1954, the author obtained a wild fox (male), Vulpes vulpes japonica (Fig. 1), from Asada, Ukiha-machi, Ukiha-gun, Fukuoka Prefecture in Japan, bred it in an iron cage for four months, and waited until it became tame. Its daily life was observed, and, except for the detection of the eggs of Bothriocephalus taenia by an examination of feces, no egg of Gnathostoma spinigerum and any other abnormality were observed.

On' the 15th of December in the same year, 30 third stage larvas of Gnathostoma spinigerum (Fig. 2), which were removed from the muscle of Ophicephalus argus, were wrapped up in its rice food, and were fed to the fox. Several minutes later the fox felt slight nausea, but did not vomit. Since then, it has been fed the leftover food of the patients in a hospital, and the observation has been continued.

On the morning of the 28th of May, 1955, about five and a half months after ingesting the nematodes, it showed difficulty in standing and sitting, and its weight decreased from $5.1 \mathrm{~kg}$ weight at the beginning of the experiment to $3.9 \mathrm{~kg}$. It lay on its side at about half past four in the afternoon of that day, and showed Cheyne-Stokes' respiration. It was then dissected under the anesthesia of ether inhalation.

\section{AUTOPSY FINDINGS AND RESULTS OF VARIOUS EXAMINATIONS}

1) In the middle of the small intestine, a soy-bean-sized black-brown hemorrhagic necrosis at the mesentery adhering to the intestine was observed (Fig. 3), but no larva was observed. 
2) In neither the small intestine nor the large intestine was there observed a lump of food or any parasite. A little quantity of dejecta was observed in the lower part of the rectum.

3) Several views of mosaic figures were seen on the surface of the lower lobule of the liver (Fig. 4). These were thought to be the traces of lesions made by the larvas after their invasion into the liver.

4) The trachea, gullet, lung, heart, kidneys, spleen, mesentery, peritoneum, abdominal wall, diaphragm, pleura, chest wall, muscle, and subcutis were examined in detail, but remarkable changes were not observed. The larvas orr the imagines of this nematode, especially, were not found at all.

5) The views of the stomach wall:

The stomach was taken out. When the stomach hollow was opened by lengthwise incision from the minor curvature, a thumb-sized tumor was found at the fundus of the major curvature (Fig. 5).

In the middle of the tumor inside the stomach about a two $\mathrm{mm}$ diametral hole was opened, but inside the stomach hollow the parasite was not found at all. The stomach was empty of foods or other contents. Around the ventricular corpus and the pylorus, ten odd millet-grain-sized red-brown hemorrhage spots were observed (Fig. 6).

The tumor of the stomach wall was cut lengthways from the small hole, and in the hollow of the tumor nine imagines were found (Fig. 7). These imagines were, after various examinations, ascertained to be those of Gnathostoma spinigerum, three males and six females (Fig. 7, 8, 9, 10, 11, 12).

6) These imagines were measured. The average body width and length of the three males was $1.5 \mathrm{~mm}$ by $18 \mathrm{~mm}$ respectively, while the average value of the six females was $2.3 \mathrm{~mm}$ by $24 \mathrm{~mm}$ respectively.

7) The dejecta in the restum was taken by the egg-gathering method (precipitation method) and was examined microscopically. Many of the fertilized eggs of this Gnathostoma spinigerum (Fig. 13,14) were detected, as well as the eggs of Diphyllobothrium mansoni.

On the other hand, many fertilized eggs of Gnathostoma spinigerum were found in the uterines of the females of this nematode, which were in the stomach tumor of the fox, as noted above (Fig. 15).

8) The many parasitic fleas on the exterior of the fox body were killed by the insecticidal powder of $\mathrm{BHC}$ (benzene hexachloride or 1, 2, 3, 4, 5, 6-hexachlorocyclohexane), and picked up. They were identified as the dog flea (Ctenocepinalides canis) upon examination (Fig. 16, 17).

\section{SUMMARY ANI DISCUSSION}

The final hosts of Gnathostoma spinigerum in cats and dogs were confirmed in the natural infection and the experimental infection, but cases of natural and experimental infections were not found in the fox.

In the infection of cats and dogs, it was said to take three to five months to experimentally evacuate the eggs in the feces after ingesting the larvas; but in this experiment, as an examination of the stool was not done after administering the larvas, the beginning 
time of the egg evacuation was not confirmed.

In the case of the fox, however, in a manner similar to the cases of cats and dogs, a typical stomach tumor was grown at just the same part, and the imagines were kept inside the tumor opened to the stomach hollow. These closely resembled the former two, and this was thought to be natural, judging from their zoological familiarity in their categories.

No parasite was found in the hemorrhagic necrosis at the mesentery adhering to the outside wall of the small intestine, and the cause of the growth of the hemorrhagic necrosis was not found. It was thought that this necrosis was perhaps a disorder caused by the movement of the larvas, and this was substantiated by the findings of the mosaic figures on the surface of the lower lobule of the liver.

The detection of the fertilized eggs of Gnathostoma spinigerum in the feces confirmed the facts that the imagines in the tumor had matured, and the males and the females continued to live.

The parasitic fleas on the body of the fox were ascertained to be dog fleas.

\section{CONCLUSION}

Up to the time of this experiment, the final hosts of Gnathostoma spinigerum in tigers, cats, dogs and leopards in the natural infection, and cats and dogs in the experimental infection ascertained were.

The author removed the third stage larvas of Gnathostoma spinigerum from the muscle of Ophicephalus argus, a kind of the fresh-water fish, and administered them perorally to a fox, Vulpes vulpes japonica.

Subsequently, five and a half months later a typical stomach tumor was found, just as in the cases of cats and dogs, and nine imagines of this nematode (three males and six females) were discovered inside the tumor. Also the fertilized eggs of this nematode were detected in the feces in the rectum of the animal.

According to these results, the author confirmed experimentally that the fox, as well as cats and dogs, was able to serve as a complete final host of Gnathostoma spinigerum. The fox was therefore added as a new final host of this nematode.

- Research, however, is continuously regarding the existence of the natural infection of Gnathostoma spinigerum in the fox.

\section{REFERENCES}

1. Brumpt, E. : Précis de Parasitologie. I, 1040, Paris, 1936.

2. Piekarski, G. : Lehrbuch der Parasitologie. 416-417, 1954.

3. Chander, ASA C. : Introduction to Parasitology. 487-489, John Wiley \& Sons, Inc., New York, 1955.

4. MiYAZAKI, I. : On the outline of the gnathostomes. Japanese Journal of Clinic and Experimental Medicine. 30:929-936, 1953.

5. MiYAZAKI, I. : On the Gnathostoma in Japan. Japanese Journal of Sanitary Zoology. 4 (Special Number): 17-24, 1954.

6. MiYAZAKi, I. : Gnathostomiasis. Japanese Journal of Parasitology. 4:111-120, 1955.

7. MiYAZAKI, I. : Studies on Gnathostoma occurring in Japan (Nematoda : Gnathostomidae). 
I. Human Gnathostomiasis and Imagines of Gnathostoma. Kyushu Memoirs of Medical Sciences. 5(1): 13-27, 1954.

8. MIYAzaKi, I. : Studies on Gnathostoma occurring in Japan (Nematoda: Gnathostomidae). II. Life history of Gnathostoma and morphological comparison on its larval forms. Kyushu Memoirs of Medical Sciences. 5 (2): 123-139, 1954.

The essential points of this study were expressed at the 25th Meeting of the Japanese Society of Parasitology on April 7 in 1956, and were published on the Medicine and $\mathrm{Bi}$ ology, Vol. 38, No. 5, 152 154, 1956 (in Japanese).

\section{ACKNOWLEDGEMENT}

At the end of this treatise, the author expresses deap gratitude to his respected Professor I. Miyazaki of the Department of Parasitology of the Kyushu University Medical School, who have always kindly guided the author, advised him and aided hitn with revision, also to Dr. T. Kikuchi and Dr. H. Kamo of the same Department for many helpful suggestion.

\section{EXPLANATION OF THE PHOTOGRAPHS}

Fig. 1: The fox (Vulpes vulpes japonica) (male) experimentally infected with Gnathostoma spinigerum.

Fig. 2: Encysted third stage larva of Gnathostoma spinigerum removed from the muscle of a Ophicephalus argus.

Fig. 3: Macroscopical view of the lesion by the small intestine: A soy-bean-sized hemorrhagic necrosis in the mesentery adhered to the intestine is shown by sketching.

Fig. 4 : Macroscopical view of the liver of the fox experimentally infected with Gnathostoma spinigerum: Several mosaic figures on the surface of the liver are shown by sketching. 
Fig.

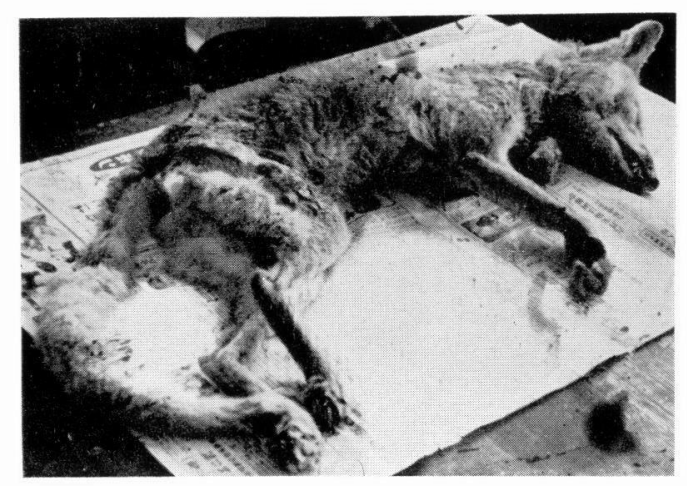

Fig. 3

cranial

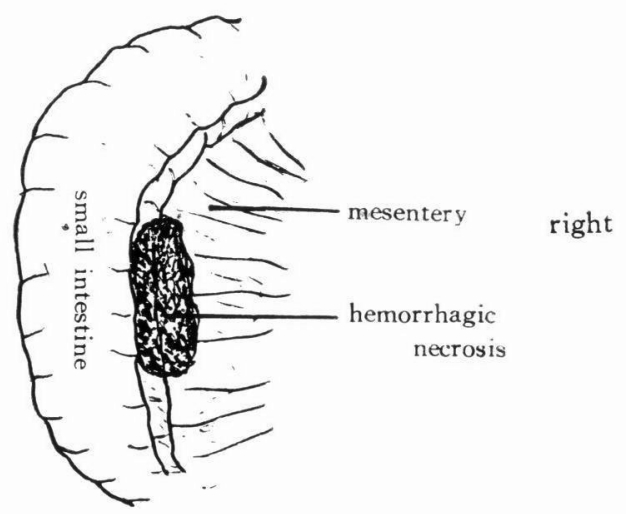

caudal
Fig. 2

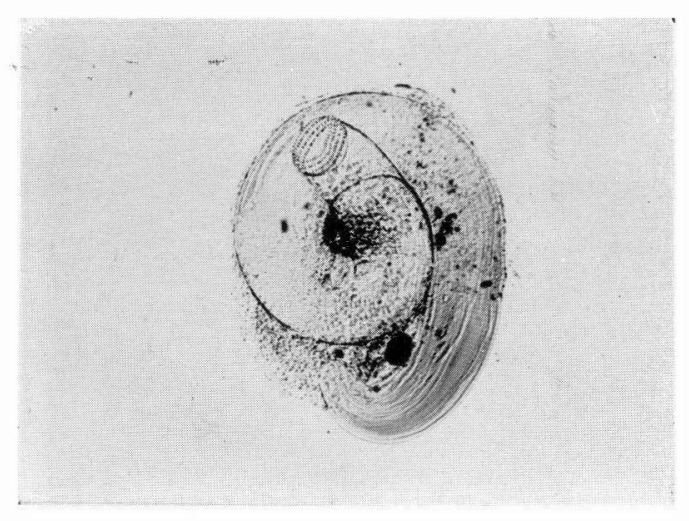

Fig. 4

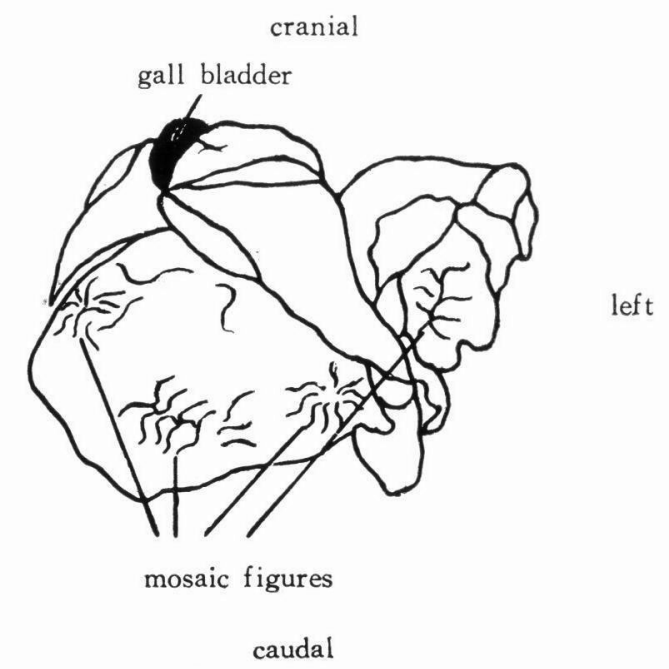


Fig. 5: A lengthways incised stomach tumor (arrow) of the fox experimentally infected with Gnathostoma spinigerum in which 9 adult worms ( 3 males and 6 females) were inhabited.

Fig. 6: Around the ventricular corpus and the pylorus, ten odd millet-grain-sized red-brown hemorrhage spots (arrow) are observed.

Fig. 7 : Nine adult worms ( 3 males and 6 females) of Gnathostcma spinigerum removed from a stomach tumor of the fox. Two worms are damaged. 
Fig. 5

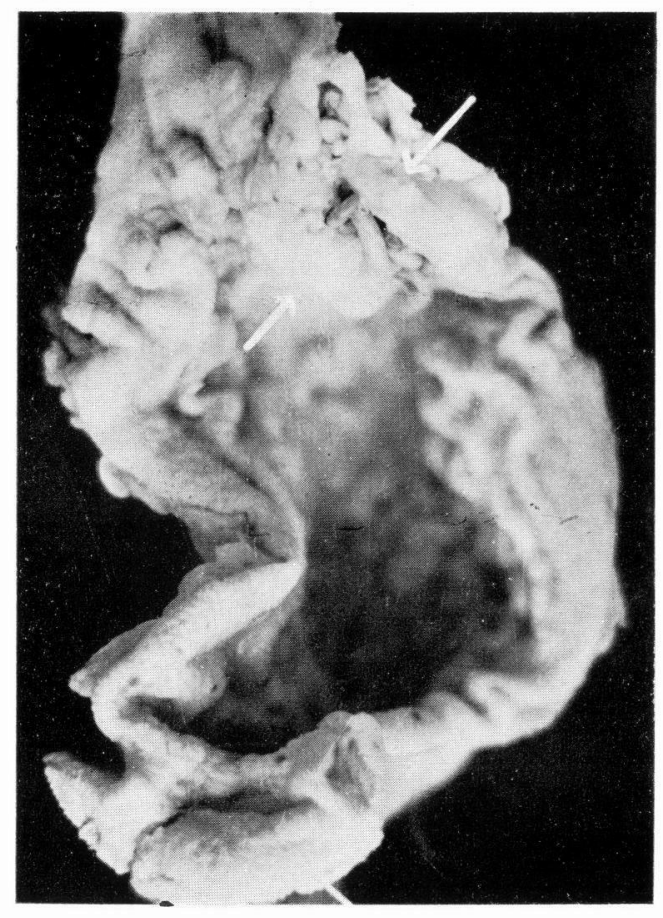

Fig. 6

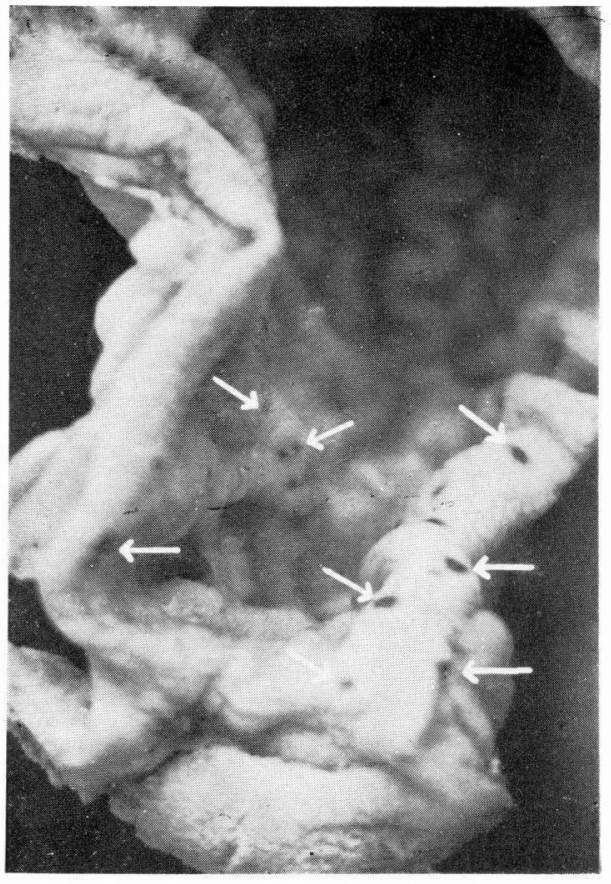

Fig. 7

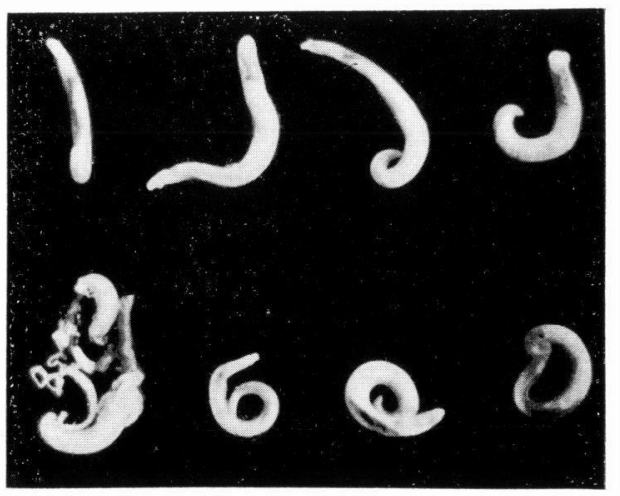


Fig. 8: A male adult of Gnathostoma spinigerum made transparent by a fixative (Neo Shigaral), and enlarged by projector.

Fig. 9: A female adult of Gnathostoma spinigerum made transparent by a fixative (Neo Shigaral), and enlarged by projector.

Fig. 10: A head-bulb of the female adult shown in Fig. 9. 
Fig. 8

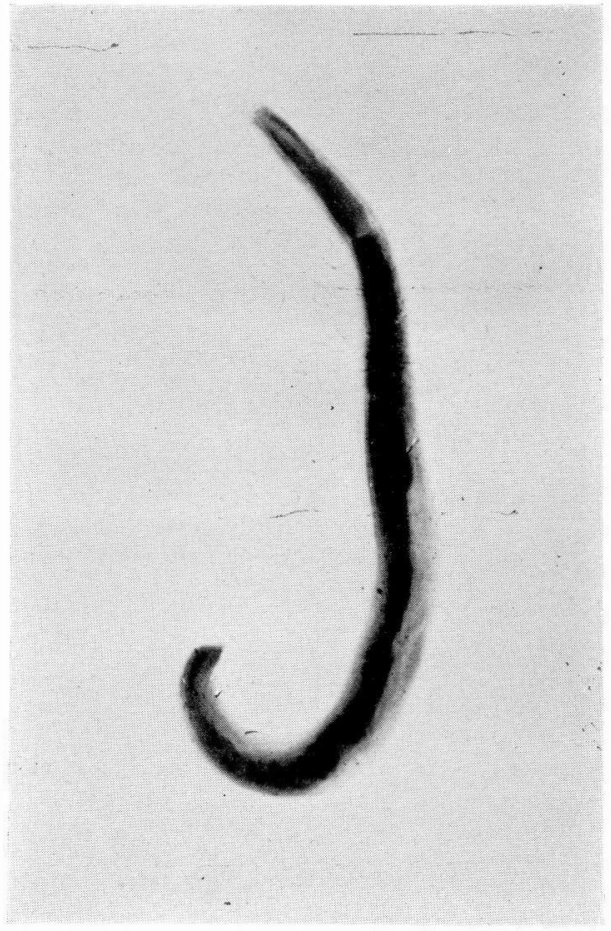

Fig. 9

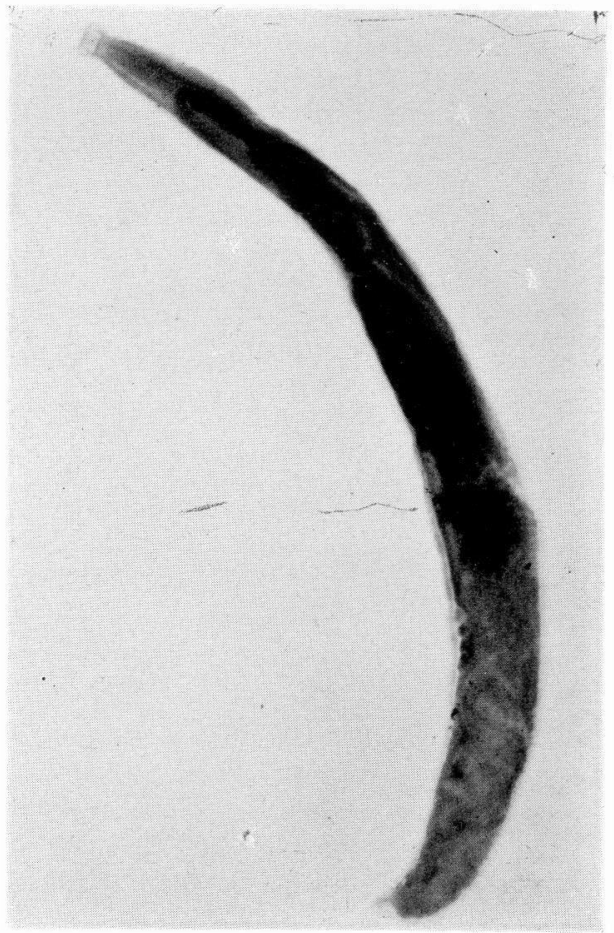

Fig. 10

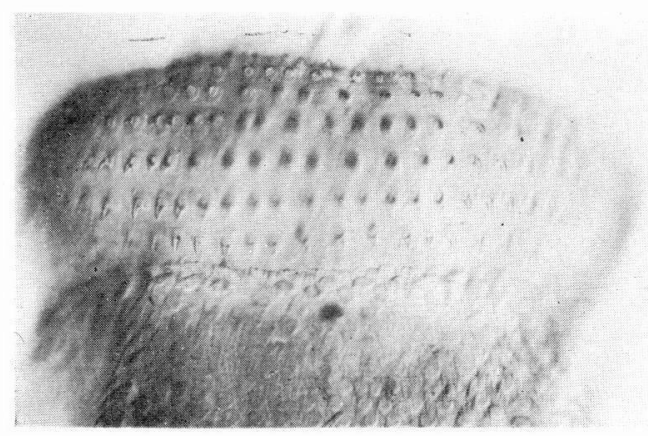


Fig. 11: A female adult of Gnathostoma spinigerum made transparent by a fixative (Balsam Capada), and enlarged by projector.

Fig. 12: A head-bulb of the female adult shown in Fig. 11.

Fig. 13: A fertilized egg of Gnathostoma spinigerum in the feces of the fox experimentally infected with this gnathostome. The egg was fixed transparently by a fixative (Neo Shigaral). 
Fig. 11

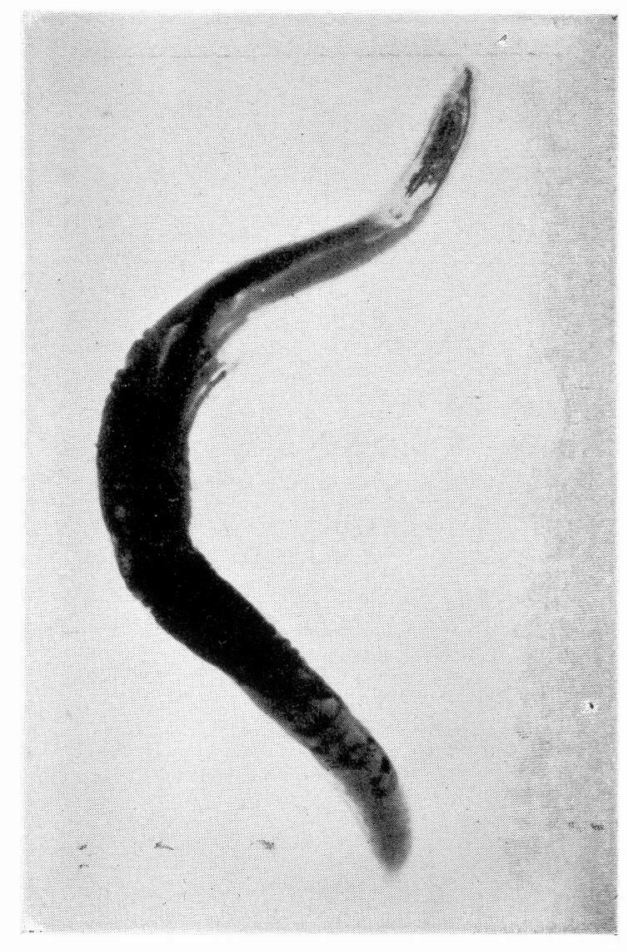

Fig. 12

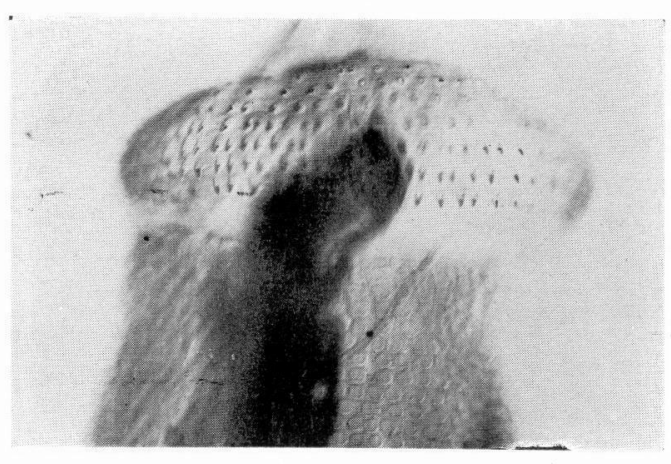

Fig. 13

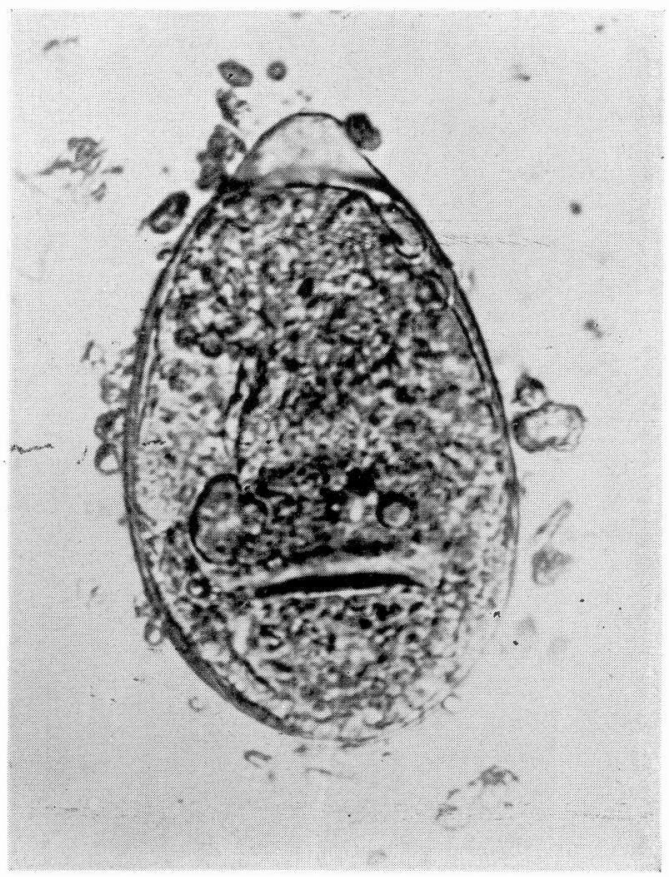


Fig. 14: A fertilized egg of Gnathostoma spinigerum in the feces of the fox experimentally infected with this gnathostome. The egg was treated similarly.

Fig. 15: Fertilized eggs of Gnathostoma spinigerum in the uterine of the female adult of the gnathostome in the stomach tumor of the fox experimentally infected with this gnathostome. The eggs were treated similarly.

Fig. 16: A male of Cienocephalides canis parasitic on the fox body. It was fixed transparently by a fixative (Neo Shigaral).

Fig. 17: A female of Ctenocephalides canis parasitic on the fox body. It was fixed transparently by a fixative (Neo Shigaral). 
Fig. 14

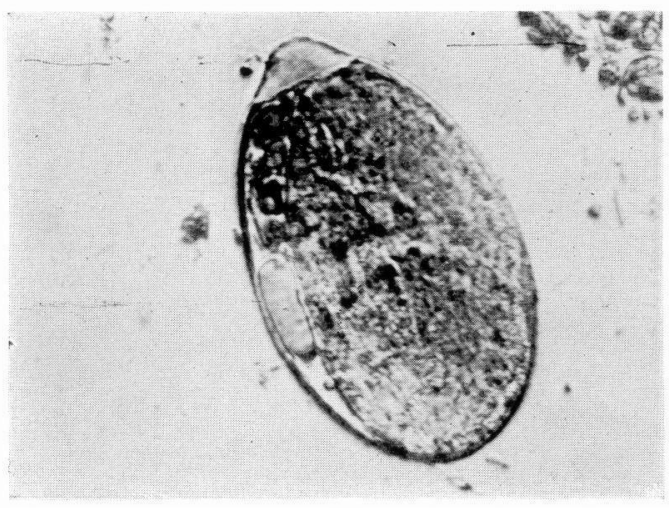

Fig. 15

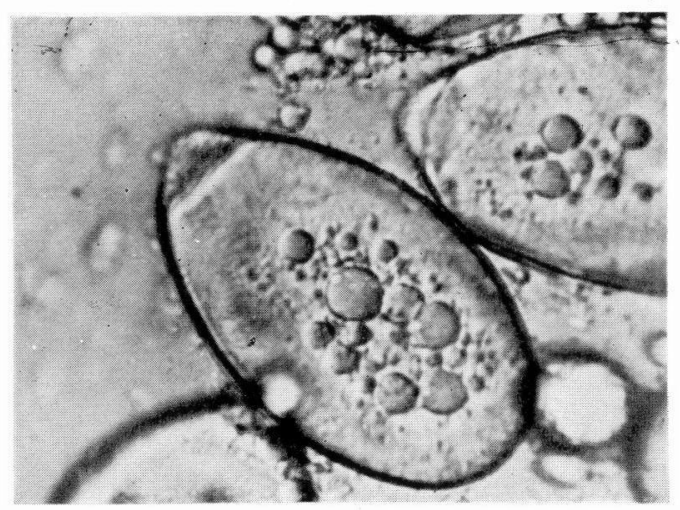

Fig. 17

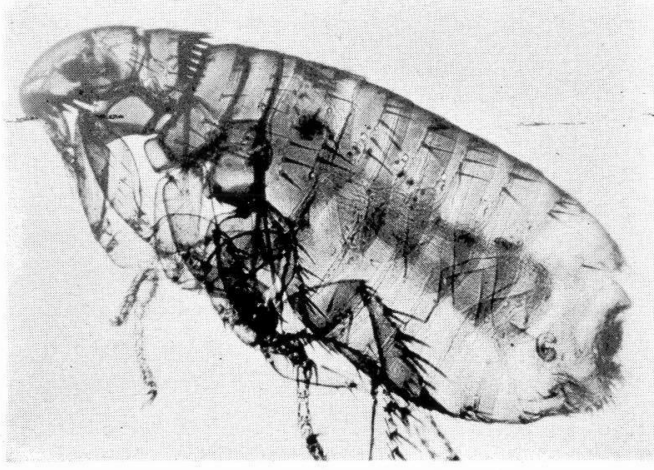

